\title{
Religião do livro, não da leitura: concepções da Torá no Israel Antigo
}

\author{
Religion of the book, not of reading: \\ concepts of Torah in Ancient Israel
}

\section{Silas Klein Cardoso*}

Universidade Metodista de São Paulo(UMESP), São Bernardo do Campo, SP, Brasil

\section{Resumo}

O artigo contesta a leitura simplista do fenômeno "Livro Sagrado" nas chamadas religiões do livro, que são percebidos apenas textual e não materialmente. Observando o contexto no qual os textos eram lidos/produzidos nos tempos do Antigo Israel - primeira religião do livro - argumenta-se que há anacronismo e partidarismo nas descrições da religião israelita, que apresentam uma fé puramente abstrata e imaterial e cujo protagonista, Moisés, escreve e lê um Livro Sagrado. Assim, tentando perceber a diversidade religiosa do Antigo Israel é apresentada uma reconstrução das concepções imagéticas do Livro Sagrado israelita como imagem de culto no período do Segundo Templo. É formulada uma tipologia das concepções do Livro Sagrado:

SKC: Doutorando em Ciências da Religião, e-mail: silasklein@gmail.com 
(1) objetos testemunho; (2) objetos mágico-oraculares; (3) objetos identitários; (4) objetos anicônicos; desenvolvimentos ulteriores.

Palavras-chave: Religiões do Livro. Livro Sagrado. Iconismo. Aniconismo. Cultura Visual Religiosa.

\section{Abstract}

The present article contests the simplistic reading of the "Sacred Book" phenomenon in the so-called book religions, which are perceived only only textual and not materially. Observing the context of reading/production of book in the times of Ancient Israel first book religion of history - we propose that that is an anachronism and partiality in the descriptions of Israelite religion, that shows a faith abstract and imaterial and which protagonist, Moses, writes and reads a Holy Book. Attempting to perceive the religious diversity of Ancient Israel we present a reconstruction of the imagetic conceptions of Israelite Holy Book in the Second Temple Period. We present a topology of this perceptions of the Holy Book: (1) testimonial objects; (2) magical-oracular objects; (3) identitary objects; (4) aniconic objects; and further developments.

Keywords: Book Religions. Sacred Book. Iconism. Aniconism. Religious Visual Culture.

\section{Introdução}

No mundo contemporâneo predominam as chamadas religiões do livro, i.e., aquelas que têm um texto como objeto central. E nas narrativas oficiais e midiáticas somos levados a acreditar que tais religiões seguem integralmente o que está escrito em seus textos sagrados, não importando a extensão ou incongruências desses escritos milenares escritos por múltiplas mãos. Isso ocorre em vários níveis. Em discussões teológicas, filosóficas e políticas, tomamos esses livros para compreender/explicar posições e atitudes. O famigerado terrorismo, por exemplo, 
é percebido como fruto de determinados capítulos e versículos bíblicos ou de tais suwar e āyāt do Alcorão. O próprio extremismo religioso por vezes é confundido com fundamentalismo ${ }^{1}$, uma posição radical frente a certos fundamentos dum livro sagrado. Entretanto, já se nota logo na superfície de tais religiões que, não há nesses textos antigos uma uniformidade teológica, tampouco existem interpretações monolíticas. Ao que parece, existem tantas seitas religiosas quanto possibilidades de leituras desses textos sagrados.

Isso ocorre porque textos são polissêmicos e lidos a partir de nossa visão de mundo. É fundamental relembrarmos aqui que toda leitura é um exercício de imaginação. Ao se distinguir o formato das letras e sua combinação em palavras e frases, o resultado não é um conceito abstrato, mas uma imagem que se forma em nossa mente. É essa imagem formada em nossa mente, o que chamamos "imaginação", que caracteriza o significado do texto. Entretanto, o grande problema da leitura é que o mesmo texto, lido por pessoas diferentes, jamais formará a mesma imagem mental. Ainda que vivamos numa mesma época e sociedade, tal imagem precisa ser abastecida pela nossa experiência pessoal (cf. WULF, 2013, p. 36-39). Por exemplo, ainda que a palavra "livro" seja conhecida por todos e que não haja grande divergência de significado, é nossa experiência pessoal que formatará a imagem mental do livro, dando-lhe cor, forma e tema, gerando, assim, para ele, uma infinidade de novos significados.

É provocativo então, nesse nosso mundo contemporâneo de religiões do livro, tentarmos nos aproximar das "imagens do livro" naquela que é considerada a primeira religião do livro da história: a religião do Israel Antigo. Argumentamos que o livro sagrado da religião israelita pós-exílica, a Torá (na tradição cristã: Pentateuco), não era percebido como livro em nosso sentido moderno da palavra, mas que cada nicho da religião israelita o entendia de forma distinta, por razões que podem ser percebidas no corpus literário da Bíblia Hebraica. Acreditamos que tal olhar para o passado seja fundamental para compreender e discutir nosso mundo

1 Vasconcellos (2008) apresenta duas dimensões do fundamentalismo: (1) a defesa da verdade traduzida em historicismo, subjetivismo, socialismo; (2) a relação religião e política que deságua em militância. Há também a rejeição da hermenêutica. Textos são vistos como: objetivos, ahistóricos e escopos para a sociedade. 
atual de forma mais pertinente, num diálogo que não deve ser apenas religioso, mas humano.

\section{Livros e leitores no Antigo Israel}

Já dissemos que a interpretação não se dá pelos conceitos abstratos que as letras no papel provocam, mas pelas imagens mentais evocadas pelos signos. Isso é importante pois, ao pesquisarmos as percepções do livro sagrado, devemos primeiro tentar nos aproximar do que os antigos israelitas e habitantes do Antigo Oriente Próximo (AOP) entendiam por "livro". Corremos o risco, sem tal cuidado, de nos achegarmos ao texto como cegos, lendo as palavras do antigo idioma atribuindo-lhes imagens mentais modernas (KEEL; UEHLINGER, 1998, p. 395). Assim, ao trabalharmos sobre as palavras hebraicas sēfer (heb. texto, documento, carta, inscrição, rolo) e mĕgillah (heb. rolo²), tentaremos perceber o imaginário coletivo hebreu antigo.

\section{Caracterizações do livro nos tempos do Antigo Israel}

Três caracterizações do livro antigo podem nos ajudar a enxergar o grande abismo que marcou o imaginário antigo do contemporâneo. Primeiro, o acesso a livros na antiguidade era escasso. Antes do período helenista, na Mesopotâmia, estima-se que apenas 5\% da população sabia ler, no Egito 7\% e na Grécia Antiga 10\% (TOORN, 2007, p. 10). Se nos grandes centros urbanos prevalecia tal proporção, em Israel e Judá, sociedades agrárias e, em grande parte de sua história, periféricas, o número era ainda menor (RÖMER, 2008, p. 52; SCHNIEDEWIND, 2004), ao que se sugere que menos de $1 \%$ da população era habilitada à leitura (RÖMER, 2008, p. 52). Outro exemplo da falta de acesso aos textos é que mesmo existindo bibliotecas na antiguidade, sua abertura às populações só se

2 É interessante perceber no texto de Ez 2: 9, o mĕgillat-sēfer, as palavras para "rolo" e "livro" juntas. 0 que comprovaria a utilização de sēfer como "escrito" ou "texto". 0 termo seria bem traduzido por "rolo escrito".

Rev. Pistis Prax., Teol. Pastor., Curitiba, v. 9, n. 1, 329-350, jan./abr. 2017 
deu no séc. XIII EC, antes eram voltadas a escribas, aristocratas e monges (CAVALLO; CHARTIER, 1997, p. 23).

Segundo, mesmo quando havia acesso à leitura, sua materialidade era distinta. Os textos, entre os anos 2800 e 600 AEC eram escritos em sua maioria em tabuletas de argila, planas na parte superior com um lado convexo. A compilação de tais textos com uma capa de argila era o que talvez mais se aproximava do livro moderno (KALLENDORF, 2013). Na mesma época, os papiros surgiram no Egito, vindos de uma planta aquática de mesmo nome. Sua compilação, a colagem de folhas no tamanho do papel comum, formavam os rolos (LEMAIRE, 1992). Ainda existiam outras formas de leitura, como o pergaminho de couro, pouco utilizado em rolos por seu grande peso e que só ganhou popularidade da disputa entre as bibliotecas de Ptolomeu V (Egito, 205-182 AEC) e Eumenes II (Pérgamo, 197-159 AEC). De qualquer forma, a materialidade, postura e manejo modificavam a interpretação dos textos ${ }^{3}$.

Terceiro, as práticas de leitura eram diferentes das que temos hoje. A palavra hebraica para leitura, $q r$ ', significa, literalmente, "exclamar, falar em alta voz". O próprio profeta Isaías admite que o livro era para se ouvir, não para se ler, quando diz: "naquele dia, os surdos ouvirão o que se lê" (Is 29:18) e Platão, defendendo a proclamação frente a inovação da leitura silenciosa diz, em Fedro, que o texto sem seu leitor é indefeso contra ataques de vozes dissonantes, pois "rola pra onde quer". No período pós-exílico o texto bíblico diz "Esdras leu no livro da Lei de Deus, traduzindo e dando o sentido: assim podia-se compreender a leitura" (Ne 8:8). A leitura era aos ouvidos do povo e, nem assim, era compreendida. Assim, a percepção do texto pela população comum não era de um "compêndio de ideias”, como erroneamente se deduz nas atualizações dos textos sagrados, mas sua materialidade imperava.

3 McKenzie (1999) questiona a possibilidade de se atingir a intenção do autor, dada a distinta materialidade dos objetos de leitura: "new readers of course make new texts, and that their new meanings are a function of their forms. The claim then is no longer for their truth as one might seek to define that by an authorial intention, but for their testimony as defined by their historical use". 


\section{Caracterização dos leitores nos tempos do Antigo Israel}

Se o acesso era tão restrito, quem eram os escritores e leitores do Antigo Israel? A escrita e utilização dos textos, em Israel, parece ter sido prática especializada de escribas que escreviam rolos para benefício de outros escribas e não para um público privado ou mercado editorial (TOORN, 2007, p. 51). Tais escribas, no AOP, eram uma parcela de intelectuais que, além da leitura e escrita, carregavam o conhecimento da cultura e de idiomas de diversos povos antigos ${ }^{4}$, além de conhecimentos para futuras "especializações" nas quais poderiam trabalhar, como: astrologia, exorcismo, adivinhação, cura e canto cultual. Cada uma dessas matérias, na Mesopotâmia, tinha seu próprio corpus de textos didáticos para aprendizado e prática. Até os reis invejavam a sabedoria desses sábios e a eles se comparavam em textos (Cf. TOORN, 2007, p. 54).

Delimitando ao contexto do Israel Antigo, os escribas aparecem sob os termos sōfēr (heb. escriba) e hạāām (heb. sábio, Cf. Jr 8:8-9). Sua presença é sentida desde o pré-exílio (cf. Jr 2:8) e, mesmo que não se configurassem como classe social, tinham ethos comum (NEWSOM, 2004, p. 37). Estavam alocados no templo ou palácio, centros financiadores da escrita (TOORN, 2007, p. 82). As fronteiras entre religião e estado, deve-se anotar, eram nebulosas. A educação deve ter tido seu centro nos templos, embora a prática fosse pessoal e, talvez, individualizada (cf. Sl 119:99-100; Pv 5:12-14; Is 50:4). Com o tempo e como fruto da ascensão do livro ao centro da religião israelita, criou-se uma rivalidade entre escribas (sábios) e sacerdotes (santos) $)^{5}$. Os escribas foram elevados à uma posição proeminente, pela responsabilidade de ensinar ao povo (2Cr 17:10). Embora não fosse um ofício de mulheres - no AOP apenas as princesas aprendiam a escrita para cultivo pessoal (TOORN, 2007, p. 55, 76) - é notável que no

4 Na Mesopotâmia, escribas eram treinados também no Sumério e Acádio. Veja também o episódio de 2Rs 18: 26, onde os emissários de Ezequias comunicam-se com o idioma aramaico com os estrangeiros.

5 Visível na oposição entre levitas e sadoquitas, onde os primeiros são relegados a cargos inferiores no Segundo Templo. Levitas teriam se tornado juristas intérpretes da Torá, no texto de Crônicas (cf. 2Cr 17:9-10). Veja a disputa em Ez 44:10; 23-24. 0 embate toma outras direções, não somente no ambiente do templo, se aceitarmos a hipótese de que os Hasmoneus eram sadoquitas (SCHOFIELD; VANDERKAM, 2005, p.73-87). 
Israel Antigo o papel da escriba mulher pode e deve ter existido, como se pode ver no clã Soferet, das listas de repatriados ${ }^{6}$.

A centralização da Torá também parece ter criado novos grupos de escribas, com práticas diversas. Carol Newsom destaca ao menos quatro vertentes: (1) vertente sapiencial, como se vê em Ben Sirác; (2) vertente jurídica, vista nos levitas; (3) vertente apocalíptica, vista em Daniel; e (4) vertente sectária, como observada em Macabeus, no deslocamento do “conhecimento da Torá" pelo "zelo pela Torá" (NEWSOM, 2004, p. 23-75). Segundo Grabbe (2014, p. 114-119), outras atribuições escribais eram suas funções administrativas, de registro de atividades, relatórios, contas e impostos. De fato, o termo escriba pode remeter desde ao alfabetizado até o alto oficial do governo. Nesse aspecto, poderiam ser comparados aos secretários, incluindo em cargos altos, como secretários de estado. Também havia o encargo da atividade literária, conselhos, registro (cópia/ produção) e literatura religiosa, que poderiam ou não ter ligação com os sacerdotes. Segundo Toorn (2007, p. 110), o ofício escribal acontecia em seis práticas distintas: (1) transcrições de informação oral; (2) invenção de novos textos; (3) compilação de informações existentes, orais ou escritas; (4) expansão de textos herdados; (5) adaptação de textos existentes para novas audiências; e (6) integração de documentos individuais em composições mais compreensivas. Nesse aspecto, Römer, refutando a ideia (medieval) dos escribas como copiadores servis de textos, lembra que "copiar um rolo significava sempre transformação” (RÖMER, 2008, p. 54).

\section{0 livro como sagrado no Israel Pós-Exílico}

A partir do panorama exposto, podemos pensar nas percepções do livro enquanto objeto sagrado. E é necessário assumirmos, de princípio, que a materialidade media a crença. Isto é, objetos materiais representam ou constituem a presença divina nas mais diversas religiões e, em especial, no ambiente do AOP. É por meio do tocar, do vestir, do ofertar, do degustar e do caminhar em direção ao solo sagrado que a experiência

6 Cf. Ed 2:55; Ne 7:57, que mencionam os “filhos das Soferet” (běnê-hassōperet). 
da fé ocorre. Mesmo nas religiões da região que não tinham estátuas com formas humanas ou animais como centro - chamadas religiões anicônicas ${ }^{7}$ -, a materialidade era central. No culto ao Deus egípcio Aten, por exemplo, raios solares representavam sua presença. O culto a Amon, em Tebes, tinha uma pedra no lugar da divindade, assim como no culto dos nabateus de Petra. Indícios de religiosidades semelhantes podem ser percebidas na arábia pré-islâmica.

Defendemos que a religião israelita pós-exílica funcionava nos mesmos moldes das religiões do AOP e que a distinção icônica e anicônica, não se refletia na prática cúltica. Isto é, mesmo que não tivesse imagens antropomórficas, sua prática religiosa era similar as religiões com imagens por centro. Sendo nosso objetivo traçar uma tipologia das concepções imagéticas do livro sagrado israelita, utilizaremos o conceito de Cultura Visual Religiosa de David Morgan, que estuda as práticas religiosas para delas fazer reluzir conceitos. Nesse ínterim, Morgan (2005, p. 52-74) traça sete funções que definem e distinguem imagens religiosas de não-religiosas: (1) ordenam espaço e tempo, i.e., definem espaços sagrados, criam e fazem manutenção da memória; (2) formam comunidades, i.e., tornam-se o símbolo sob o qual grupos se definem; (3) comunicam com o divino ou transcendência, i.e., fazem a comunicação humano-divindade e divindade-humano; (4) incorporam formas de comunhão com o divino, i.e.; (5) colaboram com outras formas de representação sejam visuais, sonoras, táteis etc; (6) influenciam o pensamento e comportamento por persuasão ou mágica, i.e., trazem valores, ideias, informações e sentimentos que seus utilizadores compreendem; (7) deslocam imagens e ideologias rivais, i.e., atuam no deslocamento de imagens e ideologias rivais, levando à destruição, dano ou remoção de imagens concorrentes (iconoclastia). Disso, exporemos modelos de percepção dos textos no Israel Pós-Exílico.

\footnotetext{
7 Mettinger definiu aniconismo como "cultos onde não há representação icônica da deidade (antropomórfica ou teriomórfica) servindo como símbolo central ou dominante de culto". Eles corresponderiam, na teoria do símbolo de Peirce, o índice. Iconismo, por sua vez, seriam aqueles que possuiríam representação icônica da deidade como símbolo central, correspondendo ao ícone (METTINGER, 1997).
}

Rev. Pistis Prax., Teol. Pastor., Curitiba, v. 9, n. 1, 329-350, jan./abr. 2017 


\section{Livros como objetos testemunho}

Uma primeira forma de percepção dos objetos-texto na literatura bíblica é a de objeto testemunho. A palavra hebraica ' $e d$, que traduzimos por "testemunho", utilizada diversas vezes no cânon para textos, tem função de identificar um conjunto de pessoas, por vezes em caráter nacional e legal (KOEHLER et al, 1999, p. 789). Assim, constitui uma entidade sócio-política/sócio-religiosa. Como anotamos, imagens religiosas têm função de fazer com que humano e divino caminhem juntos. No Antigo Israel, a ligação entre povo e divindade se dava por meio de um objeto material, que no pós-exílio passou a ser o "livro" ou "rolo" (sêfer) da Torá. Assim, textos assumem caráter simbólico distante de sua textualidade e, por consequência, sua escrita e posicionamento os tornam personagens em processos jurídicos: testemunhas. Quatro trechos da Bíblia Hebraica nos servem por exemplo.

Primeiro, temos o texto de $1 \mathrm{Sm}$ 10:17-27, que apresenta o sorteio de Saul como rei. Interessante é observar que em 1Sm 10:25, Samuel expõe o direito da realeza ao povo o escrevendo num livro (heb. wayyiktōb bassēfer), depositando-o diante de Javé (heb. wayyannah lifnê yěhwah). A atitude de colocar o objeto diante de Javé demonstra sua função de testemunhar o acordo entre divindade e povo. A conotação é ritual político-religiosa, funcionando como confirmação da aliança entre duas partes, o povo e novo rei, por meio do sacerdote.

Um imaginário similar é encontrado nos textos de Ex 24:3-8 e Js $8: 30-35$. O primeiro texto, especialmente Ex 24:7, fecha um ciclo textual de uma aliança, que havia sido iniciada em Ex 19. O texto de Js 8:32-35, por sua vez, apresenta uma escrita ritualística na frente de toda assembleia israelita (heb. kol-qěhal yiśrā'êl). As duas perícopes expõem um ambiente de tratado, onde a escrita do livro faz o papel de testemunha ritual num processo de aliança.

No quarto e último texto, que encerra o livro de Josué (24:2628), temos a expressão "Rolo da Torá de elohim" (heb. bĕsēfer tōwrat 
'ělōhîm) ${ }^{8}$, que serve como testemunho (heb. 'édah) a ser guardado pelo povo que entrava na terra. É interessante a união de objetos cúlticos antigos para ratificar o posicionamento frente a divindade, com intenção contenciosa ${ }^{9}$.

Em suma, textos funcionaram como testemunhas em processos político-religiosos. Como ressaltou Niditch (1996, p. 79), "o objeto escrito numa configuração oral-traditiva [...] funciona mais plenamente em sua função simbólica como testamento para um senso de grupo de um povo, como lembrete do que é importante". Assim, personificados na materialidade, os textos (1Sm 10:25) e escrita (Ex 24.4; Js 8:30-35) operaram como testemunhas em processos jurídicos, além de funcionarem como testemunhas de alianças (Js 24:26-28).

\section{Livros como objetos mágico-oraculares}

A segunda característica assumida pelos textos na literatura bíblica é a de objetos mágico-oraculares. O texto, aqui, é retratado como objeto mágico, capaz de amaldiçoar/abençoar. Por consequência, a materialidade dos textos surge como veículos do poder da divindade, possibilitando a comunicação com ela ou tendo papel divinatório. Como Morgan assinalou, imagens religiosas têm função de intermediar a comunicação com o divino e, assim, funcionam para influenciar o comportamento via persuasão e/ou mágica. Essa característica surge nítida em dois textos da Bíblia Hebraica, que apresentamos abaixo.

Em Ez 2:8-3.3, o profeta é convidado a abrir a boca e comer o livro. O texto é vívido na representação sensorial: o rolo é tocado, manipulado (2:9), experimentado e comido (3:3), ouvido (2:8), visto e lido (2:910). Há contraposição da sensação evocada pelo texto experimentado na escrita e paladar. Enquanto o texto traz Lamentações (heb. qinîm),

8 Que só surge duas vezes na Bíblia Hebraica, aqui e em Ne 8:18, que poderia ser um título ao Hexateuco, em contraposição à "Torá de Moisés”, título para o Pentateuco, mais breve (RÖMER, 2008, p. 179-180).

9 Além dos objetos heterodoxos postos como testemunha contra o povo, há a menção a Siquém, que no período Hasmoneu foi base para os samaritanos e tornou-se símbolo da perdição de Israel Norte. A leitura divergente da LXX, que utiliza Silo ao invés de Siquém, reforça o argumento (CARDOSO, 2015b, p. 59-71).

Rev. Pistis Prax., Teol. Pastor., Curitiba, v. 9, n. 1, 329-350, jan./abr. 2017 
gemidos (heb. wāhege) e 'ais' (heb. wāhî), seu gosto é doce como o mel (heb. kidbash lěmātōwq, cf. Sl 19:10;119:103). O aceitar a palavra de Deus é doce. Da mesma forma, a casa de rebeldes (heb. kěbêt hammerî), o povo, é contraposta ao filho do homem (heb. ben-'ādām), i.e., não querem ouvir as palavras do rolo (3:7-9), enquanto o profeta as aceita e come para se tornar espécie de "proto-humano". O texto revela o processo de mudança da profecia em atividade literária (Cf. Is 30:8; Jr 17:1), sem deixar de apresentar a característica material e sobrenatural do texto-divino (STAVRAKOPOULOU, 2005, p. 230).

Já no texto de Nm 5.11-31, há uma instrução legal que trata de casos onde a mulher foi infiel (heb. ma 'al), de forma oculta (heb. ' $/ m$ ). A legislação bíblica expressa que, quando o espírito de ciúmes (heb. rûah-qin 'ah) viesse sobre o marido, ele deveria levar a esposa ao sacerdote e executar uma série de ritos em prol de verificar sua culpabilidade. É um ordálio, uma forma antiga de julgamento que convoca a deidade para revelar culpa ou inocência dos participantes do processo, num mundo sem ciência investigativa forense (KNIERIM, 2005, p. 82). No ordálio de Nm 5, as palavras do "mundo material" são empregadas nas fronteiras do espaço sagrado, juntamente com a areia sagrada do tabernáculo, um vaso de terra, água sagrada e cabelo humano, para criar o líquido de poder (STAVRAKOPOULOU, 2013, p. 224). Há magia, que envolve a palavra escrita frente aos iletrados do período (NIDITCH, 1996, p. 83), o mesmo contexto cultural que ressoa, de outra forma, em $\mathrm{Ne} 8$.

Os exemplos carregam um imaginário onde a materialidade dos escritos são veículos do poder da divindade, tornando-se canais de comunicação para com ela. Também há influência do comportamento daqueles que aderem ao ritual. No caso de Ezequiel, o profeta torna-se portador da mensagem divina que troca de forma e, no caso do ordálio, a resposta ao processo altera o destino da mulher acusada de adultério. Ainda que não haja, neste tópico uma explícita referência à Torá, a escrita torna-se mágica na Torá tanto em Js 8:30-35, quanto torna-se objeto para consultas oraculares em Esdras e 1Macabeus (cf. na página seguinte). 


\section{Livros como objetos identitários}

Os textos também são percebidos enquanto objetos identitários. Essa faceta, ligada à textualidade, revela a capacidade de imagens religiosas formarem comunidades de fé, congregando-as ao redor de uma mesma insígnia. O símbolo da fé torna-se objeto pelo qual definem-se os grupos e, por consequência, a espiritualidade envolve o culto centralizado nesse objeto. Tal espiritualidade, no caso da Torá, teria se fundamentado sobre duas bases: (1) enquanto religião oficial, foi imperativo elaborar uma síntese teológica completa frente à ruptura samaritana e primeiros contatos com o mundo grego; e, (2) enquanto religião popular, surgiu um novo tipo de teologia, que apresentava síntese de grande alcance e tom judaíta (ALBERTZ, 1999, p. 770-782). Essa espiritualidade pode ser percebida em três exemplos.

Primeiramente, temos o mito fundante da escola deuteronomista. Em 2Rs 22-23, Josias encontra o "Rolo da Torá" (heb. sēfer hattōwrah). É importante assinalar que o tema é uma alteração de um topos literário popular, encontrado em inscrições reais da Antiguidade, cujo encontro de uma pedra fundamental que permite a reconstrução ou reforma no templo. No caso de Josias, não se encontra a pedra fundamental, mas o rolo, (novo?) fundamento da religião israelita que, segundo retórica josiânica, substituiria o templo, profeta e rei (RÖMER, 2014, p. 199). Assim, congrega-se, nos pós-exílio, uma comunidade em torno do livro.

Em Sl 119 temos um salmo acróstico. Textos acrósticos, como o Sl 25; 119 provavelmente eram utilizados na formação de escribas, para aprendizado de técnicas de escrita e para aquisição de um maior vocabulário. Os mestres citados em S1 119:99-100 seriam os escribas mais antigos (TOORN, 2007, p. 99). Embora o significado de Torá no Salmo seja contestado, é notório que um grupo se reunisse em torno desses textos.

Temos imaginário similar no Sl 1. O salmo opera como abertura para todo o saltério (DAHOOD, 2008, p. 1), segundo a editoração pós-exílica em cinco livros, contrapõem-se, como chave de leitura ao livro as figuras do justo (heb. șaddîq) e perverso (heb. $r \bar{a} s h \bar{a}$ '), próprias do ambiente litúrgico sinagogal (GERSTENBERGER, 1988, p. 29, 43). Isso se torna explícito ao percebermos que as palavras Torá (heb. tōwrah) e 
prazer (heb. hêfeș) se unem no "meditar" (heb. yehge). A palavra traduzida por "meditar" - que poderia ser traduzida como "resmungar", "rosnar", "ler em voz baixa" e "proclamar" (KOEHLER et all, 1999, p. 237) - é encontrada em textos fundamentais ao estudo do desenvolvimento da Torá ${ }^{10}$. A palavra "meditar" sugere um conceito recente de leitura. Sabemos que a leitura silenciosa (murmurar/meditar) surge na Grécia no séc. V a.C., em obras de Eurípedes (Hipólito, 428 a.C.) e de Aristófanes (Cavaleiros, 424 a.C.) (SVENBRO, 1997, p. 54-56). Assim, temos agindo no texto concepções pós-exílicas antagônicas de identidade contra alteridade.

Percebemos nessa sessão, uma face da Torá no período pós-exílico que não detém na materialidade seu centro. Neste panorama, parece lógico concluir uma evolução que tenha se dado em camadas elitizadas da sociedade pelo acesso à leitura. Aqui há, como se pode notar nos Salmos 1 e 119, o início do que se pode chamar efetivamente "Piedade da Torá". O que, segundo Albertz (2013, p. 145), significa que a Torá11 adquire papel de mediadora, onde toda confiança, esperança e amor é direcionada a ela (Sl 119:47, 97, 131) e há foco em sua meditação (S1 1:2), que revelaria a presença divina (S1 119:1-16, 73). Embora falar de uma piedade texto-cêntrica na antiguidade possa parecer um anacronismo, acreditamos ser correto pensar na Torá como conceito nesse particular espaço elitizado de escribas e altos funcionários, no imaginário tanto dos dois Salmos da Torá quanto do texto de 2Rs 22-23 ${ }^{12}$.

10 Js 1:8, como admoestação ao novo profeta de Israel; em Is 8:19 aplicada a adivinhos (heb. yiddě 'onî) e necromantes (heb. 'ōwb) e colocada em paralelo à palavra spp (heb. suspirar, chiar); em Pv 8:7 o meditar contrapõe verdade (heb. 'emet) e erro (heb. resha '), sob a voz da sabedoria (heb. ḩākmah); contraposição semelhante é encontrada em Pv 15:28, entre justo (heb. șaddîq) e perverso (heb. rāshā ${ }^{\top}$ ).

${ }_{11}$ Albertz situa o movimento no Período Helenista, tentando expressar a convergência que originaria a religião do livro judaica. Entretanto, para nós tal transição se deu ainda entre os períodos Neo-Babilônio e Persa. Já haviam indícios identitários frente ao livro no final da editoração pós-exílica como visto no mito fundante da OHD (2Rs 22-23) e, da mesma forma, é plausível pensar que em textos posteriores (Js 1; 24; Ed-Ne etc) a adoração tenha migrado para a unidade textual Torá e sua materialidade tenha sido incluída.

12 Römer (2008, p. 51-61) demonstra que os deuteronomistas eram escribas deuteronomistas e, por isso, a tipificação deles como "escola" seria acertada. A ênfase na caracterização se percebe na figura de Safã. 


\section{Livros como objetos anicônicos}

Uma das maiores inovações do período pós-exílico, entretanto, foi a utilização dos textos como objetos anicônicos. Com a maior concentração de poder nas mãos das camadas textualizadas, o objeto-texto tornou-se centro de culto, tomando o lugar - tanto na prática quanto na geografia cúltica - dos antigos ícones divinos, na reformulação teológica judaíta. Sendo uma das funções das imagens religiosas a de incorporar a experiência do divino, é notável assinalar que livro religioso, i.e., a Torá passou, com isso, a assumir não imageticamente a posição da deidade no culto, unificando o culto sob uma única insígnia que não é apenas textual-identitária, nem mágico-oracular ou testemunhal, mas uma junção dialética entre as três facetas, unidas pela prática ritualística. Três textos nos servem de exemplos.

Primeiro temos Ed 1-6. No livro de Esdras a Torá tem papel central, embora haja discussão sobre o que representa. Ao mesmo tempo que Esdras é escriba (heb. sōfēr) experimentado na Torá de Moisés (heb. māhîr bětōwrat mōshe) em Ed 7.6, ele também é escriba (heb. sāfar) da lei do Deus do céu (heb. dātā' dî̀- 'ělāh). As palavras dāt (aram. lei, decreto) e Torá (heb. tōwrah, ensino, instrução) se confundem (Cf. Ed 7.25, 26) (GRABBE, 1998, p. 140). A origem da Torá também é desconhecida, visto que especialmente em Ed 1-6, o texto aparentemente é conhecido e praticado (Cf. Ed 3.2; 6.18-22 etc) ${ }^{13}$. De qualquer forma, na estrutura literária de Ed 1-6, a Torá assume o papel da deidade. O texto segue a estrutura dos relatos de construção de templos do AOP (FRIED, 2013), suprindo a falta da entrada do Deus (i.e., estátua) no recinto, pela entrada da Torá. Assim, a Torá assume o lugar da deidade, personificada no objeto livro ${ }^{14}$, que também serve para oráculos ${ }^{15}$.

${ }^{13}$ Grabbe (1998, p. 146-147) oferece duas explicações para a incoerência: (1) a ideologia do autor, que diz que Moisés havia escrito o Pentateuco há muito tempo; (2) pela realidade histórica do "livro de Moisés", que teria tomado forma no Período Persa.

14 Fried (2013) demonstra que o ritual de purificação do caminho é outro indício da deificação do livro, também visto na dedicação do templo de Shamash por Nabonidus e no caminho da arca em 2Sm 6:12-13.

150 termo lidrōwsh, referindo-se à Torá de YHWH em Ed 7:10, normalmente é traduzido por perscrutar (BJ), estudar (NBP) ou buscar (ARA), mas pode ter conotação oracular (Cf. FRIED, 2013, p. 294).

Rev. Pistis Prax., Teol. Pastor., Curitiba, v. 9, n. 1, 329-350, jan./abr. 2017 
O segundo texto também pertence ao corpo de Esdras-Neemias. No capítulo oito, especialmente $\mathrm{Ne} 1-2,5-6$, que fariam parte de um estrato mais antigo, a Torá é recebida como um sinal físico do próprio YHWH (FRIED, 2013, p. 294; NIDITCH, 1996, p. 105-106). O texto é o único no qual o povo se prostra (heb. shhhh) perante um texto. Embora o termo tenha conotação de respeito, em alguns textos (p. ex., Gn 18:2; 19:1; 1Sm 24:9), também há a possibilidade de denotar culto e adoração (p. ex., Gn 22:5; Ex 4:31; 34.8; Nm 22:31). Na perícope de $\mathrm{Ne}$ 8:1-2, 5-6 a segunda possibilidade é mais conveniente. A fórmula litúrgica “'āmēn! 'āmēn!" (cf. Nm 5:22; Dt 27:15-26; Sl 41:13; 72:19; 89:53; 106:48 etc) e o povo ficar em pé, como à espera da palavra de YWHW (cf. Ex 20:18; 33:10; Jr 28:5; 44:15) já nos ajudariam a comprovar a hipótese, entretanto, o escritor diz que se inclinaram (heb. qdd) e se prostraram (heb. shḥh) diante de Iahweh (heb. layhwah). Ou seja, há uma relação direta entre Torá e Javé, trata-se de uma metonímia, que toma a parte (Torá) pelo todo (YHWH). O texto constitui-se, assim, na imagem do próprio YHWH.

O terceiro texto é Ex 32:15-20. O relato, com paralelo em Dt 9:821, apresenta a chegada das tábuas da lei (heb. luḥ̂t hā 'êdut) por Moisés e a contraposição ao bezerro (heb. 'égel). Enquanto as tábuas eram criações de Deus (Ex 32:16; Dt 9:10) a imagem do bezerro era criação dos sacerdotes (Ex 32:1-6, 20; Dt 9:12, 16, 21). É uma forte disputa imagética. As tábuas são chamadas de "testemunho" (heb. 'édût), ou para recordar os atos salvíficos de Deus ou como sinônimo de aliança (heb. běrît) (MEYERS, 2005, p. 131; PROPP, 2008, p. 383-385). Em contraposição, o bezerro (heb. 'égel), um touro de aproximadamente um ano de idade (cf. Lv 9:3; Mq 6:6) pode representar uma deidade tourina da antiga Samaria, como a ressonância entre Ex 32:4; 1Rs 12:28 e as inscrições de Kuntillet Ajrud denotam ${ }^{16}$. A forma como Moisés queima o bezerro no fogo, o tritura e o reduz a pó é similar a destruições de templos e imagens heterodoxas, como visto no Mito de Ba'lu e em 2Rs 23:15 (MEYERS, 2005, p. 260; CHILDS, 2004, p. 569), i.e., uma destruição de acordo com as convenções antigas (PROPP, 2008, p. 559). O diferencial do relato está na atitude

16 Provável representação do “Javé de Samaria”. (KAEFER, 2015; KEEL; UEHLINGER,1998, p. 191-192). 
seguinte de Moisés: o espalhar os restos do bezerro na água para que os israelitas beberem. Há notável similaridade ao ordálio de $\mathrm{Nm} 5^{17}$. Uma notável convergência é exposta em um mito ugarítico, em que deidade é dada aos pássaros para beberem (CHILDS, 2004, p. 572). Entretanto, é mais provável que a água amarga seja um castigo do povo, como se vê na tradição de Jeremias (Jr 8:14; 9:14; 23:15). Há clara intenção na perícope de deslocar a imagem do Bezerro do culto israelita e direcioná-la à Torá. Nesse aspecto, as tábuas do testemunho apresentam duas características das imagens religiosas: permitem a presença divina e deslocam imagens concorrentes. O foco é a adoração na imagem anicônica: a Torá.

Assim, os textos trazem a Torá como substituta visível das imagens cúlticas anteriores, tornando-se imagem anicônica de culto. Há convergência tanto nas formas de adoração frente ao objeto-texto, quanto ao seu caráter oracular. E foi, inclusive, inserido um conto didático para mudanças do imaginário cúltico: do iconismo teriomórfico ao aniconismo.

\section{Desenvolvimentos do imaginário do Livro no Período Helenista}

Nos textos da LXX, vemos que o imaginário da Torá ainda sofre mutações, embora continue a assumir práticas similares de culto. Três textos servem como exemplo.

Em Eco 24, a Torá é a totalização da personificação da Sabedoria (Eco 24:23), que toma a expressão "Livro da Aliança" retirada de Ex 24:7 e unindo-a figura do Éden, na relação com os rios tradicionalmente primitivos (SKEHAN; DI LELLA, 1987, p. 336). O texto que tem clara intertextualidade com Pv 8 (CORLEY, 2005, p. 159): a declaração em primeira pessoa ( $\mathrm{Pv}$ 8:4-36; Eco 24:3-22); a presença na criação ( $\mathrm{Pv}$ 8:22; Eco 24:9); a inversão entre céu e abismo (Pv 8:27; Eco 24:5); os riscos de se perder a sabedoria (Pv 8:36; Eco 24:22); e a figuração árborea da sabedoria (Pv 8:19; Eco 24:13-17), que bem poderia estar atrelada à figura da deidade feminina Asherá (cf. Pv 3:18; Eco 1:20). Para Ben Sirá,

17 Embora a função para ser um ordálio seja duvidosa, visto que a culpa é declarada desde o princípio do texto. 
há convergência entre os dois conceitos, expressa em Eco 19:20 (BJ): "toda sabedoria é temor do Senhor, em toda sabedoria há cumprimento da Lei, e reconhecimento de sua onipotência”. Assim, em Eco, a Torá mantém-se símbolo identitário da camada escribal-sapiencial.

Em 1Mac vemos dois imaginários distintos da Torá se unirem, um no primeiro capítulo e outro no terceiro. Como que fazendo oposição ao texto de Ed 7:26, onde se tem a "lei do rei-e-Deus" de forma positiva, em $1 \mathrm{Mac}$ 1:41-64 há um embate entre a ordem/lei do rei (gr. logos) e a lei/ Torá (gr. nomos) de inclinação claramente sacerdotal. Há um dualismo que faz com que aqueles que não se oponham à lei do rei, tornem-se "desertores da lei" (BJ, gr. pas ho enkataleipōn ton nomon, lit. "aqueles que abandonam a lei”), enquanto a oposição, por partido de Antíoco Epífanes, rasgavam (gr. kataschizō) e queimavam no fogo (gr. enepyrisan en pyri) os livros da lei (gr. biblia tou nomou, v. 56) também chamados livros da aliança (gr. biblion diathēkēs, v. 57). Assim, no ciclo narrativo de $1 \mathrm{Mac}$ 1:9-52, a razão para o mal na terra (gr. kaka en tē gē) seria a aliança com os gentios (cf. Mac 1:11). Em 1Mac 3:46ss, por sua vez, a Torá não é apenas um compêndio de normas, mas objeto de consulta oracular. $\mathrm{O}$ próprio escritor revela a semelhança entre o ato de consultar a Torá e o ato de consultar a imagem dos ídolos, demonstrando ser uma prática semelhante. O problema está no objeto de culto, não na forma de culto. A circunstância é ritualística, como os sacrifícios (dízimos e ofertas), a presença da estola sacerdotal e nazireus sugerem. Na sequência, elevam a voz ao Céu, perguntando como deveriam proceder, denotando a forma oracular de consulta.

Da literatura posterior ao cânon hebreu, então, podemos perceber a nítida necessidade de convergência sobre a Torá. Ela torna-se símbolo nacional religioso e, por isso, grupos passam a circundá-la com diversas concepções. Nesse ambiente, o livro é tanto símbolo da fidelidade religiosa, quanto receptáculo e sinônimo de toda a antiga sabedoria hebraica. Prevalece, nesse ínterim, o caráter místico da Torá, enquanto objeto para consultas oraculares, como também era visto em textos e objetos anteriores. Mesmo num mundo mais letrado, a materialidade do livro permanece com seu imaginário anterior latente. 


\section{Considerações finais}

Em nossa introdução, dissemos que hoje somos levados a acreditar que as religiões seguem o que está escrito em seus textos sagrados. Nossa ressalva a fazer coro à essa afirmação não se ergue no âmbito da teologia oficial das religiões do livro, que geralmente reafirmam seu fiel seguimento ao conteúdo do texto, mas nas práticas expostas no próprio corpo de textos sagrados que tais religiões seguem, em especial na Bíblia Hebraica ${ }^{18}$. A percepção do texto não está atrelada a uma característica imanente do texto, mas ao ambiente dos "leitores" e suas particularidades sócio-religiosas, i.e., a imagem mentalmente criada por "livro" é aquela que se compõe do imaginário comum percebido na religião, associada à percepção religiosa individual. Em suma, antes de ser um compêndio de conceitos teológicos ou históricos, o objeto-livro é um objeto de poder, uma imagem de culto, em última instância.

Acreditamos que essa característica foi exposta em nossa tipologia das concepções do livro sagrado israelita no período pós-exílico. A Torá assumiu a forma, no pequeno espaço do pós-exílio de: (1) objeto testemunho; (2) objeto mágico-oracular; (3) objetos identitários; e (4) objeto anicônico, que traduz a própria presença da deidade. Essas interpretações prático-rituais do texto sagrado são desenvolvimentos do próprio imaginário dos leitores/cultuantes que, em maior ou menor literacidade, e/ ou maior ou menor ritualismo, compreenderam a Torá de forma e em contextos particulares. Isso é acentuado na recepção da Torá na LXX, que demonstra que essas diversas concepções continuaram a concorrer no período helenista.

Pensamos ser improdutiva, então, a caracterização das religiões do livro, em especial do Antigo Israel, pela textualidade, como costuma se fazer em leituras a partir de dentro (ortodoxia/fundamentalismos) e a partir de fora (heterodoxia/análises científicas). Os textos sagrados não ordenam a religião pela imposição de conceitos via literatura e intelecção, apenas. Para isso ocorrer, deveríamos ter comunidades ideais de leitores

18 O Alcorão (3:75-79) também percebe as divergências entre fundamento/interpretação e o papel do objeto-livro.

Rev. Pistis Prax., Teol. Pastor., Curitiba, v. 9, n. 1, 329-350, jan./abr. 2017 
que compartilhassem uma mesma interpretação textual, o que é improvável. Pelo contrário, assumir um livro como sagrado consiste em elevá-lo à condição de imagem religiosa e, ao fazê-lo, ele destaca-se não apenas na geografia do culto, mas no imaginário dos leitores. Ele pode se tornar: imagem do divino, insígnia e elo entre os cultuantes, e meio de comunicação com o divino, cujas conotações mágicas estão inclusas. Todas essas vertentes podem ser encontradas nas religiosidades do livro do Antigo Israel, assim como nas religiosidades contemporâneas do livro. Fazer justiça a tais movimentos, portanto, é perceber tais compêndios de textos primeiramente em sua materialidade, que ganha porte a partir de sua percepção como grandezas hermenêuticas que devem ter suas interpretações generalizantes respeitadas na forma plural e diversa como são recebidas e lidas pelas comunidades religiosas. Se os textos sagrados geram diversidade de leituras é porque são lidos na realidade diversa e multifacetada que nos convida a um diálogo que, como dissemos, não deve ser religioso, mas centrado em nossa humanidade.

\section{Referências}

ALBERTZ, R. Historia de la religión de Israel en Tiempos del Antiguo Testamento. v. 1-2. Madrid: Trotta, 1999.

ALBERTZ, R. "Personal Piety”. In: STAVRAKOPOULOU, F.; BARTON, J. Religious Diversity in Ancient Israel and Judah. London: Bloomsburry T\&T Clark, 2013. p. 135-146.

CARDOSO, S. K. A imagem se fez livro: a materialidade da Torá e a invenção do aniconismo pós-exílico. 2015a. Dissertação (Mestrado em Ciências da Religião) Universidade Metodista de São Paulo, São Bernardo do Campo, São Paulo, 2015a.

CARDOSO, S. K. "Siquém, símbolo de Israel Norte”. Revista Caminhando, v. 20, n. 2, p. 59-71, jul./dez. 2015.

CAVALLO, G.; CHARTIER, R. História da Leitura no Mundo Ocidental. v. 1. São Paulo: Ática, 1997. (Coleção Múltiplas Escritas). 
CHILDS, V. S. The Book of Exodus: Critical, Theological Commentary. Kentucky: John Knox, 2004.

CORLEY, J. "An Intertextual Study of Proverbs and Ben Sira”. In: CORLEY, J.; SKEMP, V. (eds.). Intertextual Studies in Ben Sira and Tobit: Essays in Honor of Alexander A. Di Lella, O. F. M. Washington: Catholic Biblical Association of America, 2005.

DAHOOD, M. Psalms I: 1-50: Introduction, translation, and notes. AYB 16. New Haven/London: Yale University Press, 2008.

FRIED, L. "The Torá of God as God: The Exaltation of the Written Law Code in Ezra-Nehemiah". In: MACDONALD, N.; DE HULSTER, I. J. Divine Presence and Absence in Exilic and Post-Exilic Judaism. Tubingen: Mohr Siebeck, 2013. p. 283-300.

GERSTENBERGER, E. S. Psalms Part 1: With an Introduction to Cultic Poetry. Grand Rapids: Eerdmans, 1988.

GRABBE, L. Ezra-Nehemiah. OTR. New York: Routledge, 1998.

GRABBE, L. "Scribes, Writing, and Epigraphy in the Second Temple Period". In: ESHEL, E.; LEVIN, Y. (eds.). "See, I will bring a scroll recounting what befell me" (Ps 40.8): Epigraphy and Daily Life from the Bible to the Talmud. Gottingen: Vandenhoeck \& Ruprecht, 2014. p. 106.

KAEFER, J. A. "O Êxodo como tradição de Israel Norte, sob a condução de El e Javé na forma de touro jovem”. Horizonte, v. 13, n. 38, abr./jun, p. 878-906, 2015.

KALLENDORF, C. "Ancient Book”. In: SUAREZ, M. F.; WOUDHUYSEN, H. R. (eds.). The Book: A Global History. New York: Oxford University Press, 2013.

KEEL, O.; UEHLINGER, C. Gods, Goddesses and Images of God in Ancient Israel. Minneapolis: Fortress, 1998.

KNIERIM, R. P. Numbers. Grand Rapids: Eerdmans, 2005.

KOEHLER, L. et al. The Hebrew and Aramaic lexicon of the Old Testament. New York: Brill, 1999. 
LEMAIRE, A. “Writing and Writing Materials”. In: FREEDMAN, D. N. The Anchor Yale Bible Dictionary. New York: Doubleday, 1992.

MCKENZIE, D. F. Bibliography and the Sociology of Texts. Port Chester: Cambridge, University Press, 1999.

METTINGER, T. No Graven Image? Israelite Aniconism in Its Ancient Near Eastern Context. CB 42. Stockholm: Almqvist \& Wiksell International, 1997.

MEYERS, C. L. Exodus. NCBC. Cambridge: University Press, 2005.

MORGAN, D. The Sacred Gaze: Religious Visual Culture in Theory and Practice. Berkeley: University of California Press, 2005.

NEWSOM, C. A. Torá, Knowledge, and Symbolic Power: Strategies of Discourse in Second Temple Judaism. In: NEWSOM, C. A. The Self as Symbolic Space: Constructing Identity and Community at Qumran. Leiden/Boston: Brill, 2004. p. 37.

NIDITCH, S. Oral World and Written Word: Ancient Israelite Literature. LAI. Louisville: Westminster John Knox Press, 1996.

PROPP, W. H.C. Exodus 19-40: a new translation with introduction and commentary. AYB 2A. London: Yale University Press, 2008.

RÖMER, T. A chamada história deuteronomista: introdução sociológica, histórica e literária. Petrópolis: Vozes, 2008.

RÖMER, T. "The Case of the Book of Kings". In: EDELMAN, D. V. (ed.). Deuteronomy-Kings as Emerging Authoritative Books: A Conversation. Atlanta: SBL, 2014. p. 187-201.

SCHNIEDEWIND, W. M. How the Bible Became a Book: The Textualization of Ancient Israel. Cambridge: Cambridge University Press, 2004.

SCHOFIELD, A.; VANDERKAM, J. C. “Were the Hasmoneans Zadokites?”. JBL, v. 124, n. 1, p. 73-87, 2005.

SKEHAN, P. W.; DI LELLA, A. A. The Wisdom of Ben Sira. New York: Doubleday, 1987. 
CARDOSO, S. K.

STAVRAKOPOULOU, F. "Materialist Reading: Materialism, Materiality, and Biblical Cults of Writing". In: DELL, K. J.; JOYCE, P. M. Biblical Interpretation and Method: Essays in Honour of John Barton. New York: Oxford, 2013.

SVENBRO, J. “A Grécia Arcaica e Clássica: a invenção da leitura silenciosa”. In: CAVALLO, Guglielmo; CHARTIER, Roger. História da Leitura no Mundo Ocidental. São Paulo: Ática, 1998. p. 41-69.

TOORN, K. V. D. Scribal Culture and the Making of the Hebrew Bible. Cambridge: Harvard, 2007.

VASCONCELLOS, P. L. Fundamentalismos: Matrizes, presenças e inquietações. São Paulo: Paulinas, 2008.

WULF. C. Homo Pictor: imaginação, ritual e aprendizado mimético no mundo globalizado. São Paulo: Hedra, 2013.

Recebido: 02/10/2016

Received: 10/02/2016

Aprovado: 04/01/2017

Approved: 01/04/2017 